\title{
A systematic literature review on the effects of bullying at school
}

\author{
Tharishini a/p Mana Mohan ${ }^{1}$, Abu Yazid Abu Bakar ${ }^{\left.1^{*}\right)}$ \\ ${ }^{1}$ Faculty of Education, Universiti Kebangsaan Malaysia, Selangor, Malaysia \\ *) Correspondance: yazid3338@ukm.edu.my
}

\begin{abstract}
Bullying is a severe problem that is experienced, especially in schools. Children belong to the same social group, but some feel powerful than others and therefore take advantage of them to physically or verbally abuse them. Many institutions are aware, but most cases are not handled because most victims do not report. Therefore, only physical bullying is addressed as the impacts can be easily seen by adults. Various articles were analyzed to illustrate the different effects of bullying on the bully, the victim, and those around. The results demonstrate that bullying results in emotional, physical, and health effects and affects a victim's academic performance.
\end{abstract}

Keywords: Bullying, literature review, school, Malaysia

Article History: Received on 4/1/2021; Revised on 1/1/2021; Accepted on 19/02/2021; Published Online: 20/02/2021.

This is an open access article distributed under the Creative Commons Attribution License, which permits unrestricted use,
distribution, and reproduction in any medium, provided the original work is properly cited. (C)2021 by author.

\section{INTRODUCTION}

Bullying is an aggressive behavior shown by repetition and an imbalance of power. It involves a recurrence abuse of power where a person repetitively abuses their power. The person being bullied who is the victim cannot defend him or herself for various reasons such as less physical strength and being less psychologically resilient than the bully (Ghani, Awang, Ahmad, Jalal \& Bakar, 2020). By nature, bullying is likely to have specific features, such as the victim's fear to report, and most of the outcomes include depression and the development of low esteem in the victim. Since the victim is mostly defenseless, it implies that other people have the obligation considering that the victim has democratic rights.

Bullying occurs in different places, including schools and workplaces. The United Nations Convention on the Rights of the Child takes protection from abuse seriously as a prerequisite for a child's quality of life, and it is the child's right. In recent decades fight against bullying, but the fight is not easy. In human groups, power relationships are universal. The position of power should be managed non-abusively, but some people take advantage of their position in exploiting power. The bully is tempted to distress the less powerful person repetitively. Therefore, bully-victim relationships are normatively in the sense that they are strictly limited. They are likely to be found in any relatively successful human group challenging for someone to leave if they are victimized. 
The relationship between the bully and the victim is usually normative, especially in schools. It is an acceptable generalization that all schools can anticipate the occurrence of bullying, although with different severity degrees. The growing consciousness about bullying enables various stakeholders to admit and acknowledge that the problem is there without judging the school or the workplace as evil instead of taking necessary action steps to reduce occurrences.

Bullying typically happens in settings where the individuals lack a say concerning the group they want to belong to (Ghani, Awang, Ahmad, Jalal \& Bakar, 2020). This is the situation for children in schools or at home with siblings caged with people they do not have control over. As they try to establish a social network, bullies try to exert their power with all the children. Among them, those who show an emotional reaction, for example, crying or running away and have no one to defend them, become the targets of bullies. Other bullies join in to laugh, hit, tease or spread rumors about the victims.

Bullying can be verbal, physical, online, or exclusion. Verbal bullying is in oral or written form, including calling names, threatening to harm, inappropriate sexual comments, and abusive language. Physical bullying includes kicking, hitting, spitting, pinching, breaking the victim's belongings, rude gestures, and even ripping. Online or social bullying is about harming one's reputation through phones, computers, and social media platforms. Exclusion is whereby one is left out in activities, persuading people against a victim, public embarrassment, and spreading false rumors. Verbal bullying is the most common type, although online bullying is also on the rise.

\section{METHOD}

This study was a qualitative study where data was collected from existing literature, using the document analysis procedure. Different articles published in the last ten years were analyzed. The articles selected are those that discuss bullying at school and its effects on the victim, bully, and peers.

\section{RESUlts}

Bullying is a serious issue, especially in schools affecting children and adolescents, which have short and long-term effects on the bully, the victim, and those who observe these bullying events. Bullying can be direct or indirect, and therefore children and adolescents experience different types of bullying. The effects are physical, behavioral, mental, and health and affect the victim's academic performance and achievement (Rivara \& Le Menestrel, 2014). Being bullied makes the victim incredibly insecure. When one is bullied, they are frequently on guard and insecure such that even when one is not being bullied actively, they are aware it can start anytime. A victim's emotional and mental well-being is affected where he/she feels isolated, unaccepted, withdrawn, and angry. The victim is always thinking about how they can run away from the bully, making them have constant tension and may therefore miss out from being in environments exposed to bullying.

The physical consequences of bullying can be instant, for example, physical injury, but they can also be long-term, such as sleep disturbances, somatization, and headaches. 
However, the long-term physical effects can be challenging to point out or even link them with past bullying experiences as people may think they may be caused by anxiety or bad childhood events. Rivara \& Le Menestrel (2014) record that bullied children experience adverse physical health compared to those who are not bullied.

Those students who are bullied have difficulties in paying attention and concentrating in class. Bullying is common in schools, and student victims are likely to develop learning difficulties and concentration problems (Jan \& Husain, 2015). Students experience different bullying behaviors, the most common being verbal aggression than indirect aggression or physical aggression. Students who are bullied tend to lack connectedness with the teacher, which negatively affects their academic achievement.

Victims of bullying suffer academically because they are unable to focus on their school works. Once a child starts being bullied, their grades start slipping. Kids are preoccupied by bullying, that they fail to pay focus to academics, including doing their assignments (Dresler-Hawke \& Whitehead, 2013). They will also give their parents excuses, all aimed at missing school and classes to avoid being bullied, which affects their grades, further increasing their stress.

Bullied children suffer both social and emotional effects. Since there are people (bullies) who fear them, they find it hard to make friends or even maintain healthy friendships. This struggle is mainly because of low self-esteem due to the hurt and means words, bullies, directly. The names they are called continuously tend to believe that they are right, making them hate themselves. The victims also experience diverse emotions. They tend to be bitter, angry, vulnerable, frustrated, helpless, and isolated from people they belong to the same social group. As a result, they may avoid places where their peers are, including class, or even turn to alcohol and drugs to take their pain away. If the bullying is extreme, the victims may develop depression and even think of suicide.

The effects are worse when their a lack of intervention measures as the victims can develop learned helplessness. Learned helplessness is whereby the victims believe that the situation is beyond them and there is nothing they can do about bullying, and therefore they put no effort in stopping. This gives them the feeling of hopelessness and depression. As the children grow into adults, they continue struggling with self-esteem and have difficulties maintaining social interactions and healthy relationships. They also find it hard to trust people affecting work and personal relationships. Some victims are also involved in believing that, after all, bullying is not as wrong as it is and again blaming themselves.

Victims of bullying are more likely to start using alcohol, bang, and even smoking. In countries like North America and Europe, most bullies and bully-victims engage in alcohol use and lifetime smoking and cannabis. This has also been observed in other regions where bullied children are more likely to have smoked cigarettes, consumed alcohol, and used cannabis than those who have never been bullied (UNESCO, 2018). Bullying is also associated with earlier sexual experiences. Victims and bullies, especially adolescents aged between 14 and 15, are more likely to have had sexual intercourse than those not involved in bullying. 
Bullying is directly related to peer victimization, especially in schools. Peer victimization harms the victim's health, especially in inducing states of psychological distress and impaired physical health. Suicidal thoughts are one of the extreme consequences of peer victimization. There are reported cases of children who committed suicide due to repeated victimization (Rigby, 2011). Even though the person is already dead and therefore, it may be hard to know whether peer victimization is the actual reason most children have left notes that pointed to peer victimization. Children who have been bullied in one way or another have reported having had suicidal thoughts, which they open up during counseling when parents choose to intervene.

Bullying victims fear the environment they are bullied, including school, as they consider it unsafe and unhappy. Some even go to extreme levels of absence seem and dropping out of school. Those who choose to remain have low self-esteem, anxiety, and even depression. Due to the fear, some victims turn to produce different physical and emotional ailments (Omoteso, 2010). Such consequences may follow them even when they get into adulthood, whereby they cannot express themselves or relate well. These effects affect not only the bullies but also children who witness bullying. They suffer from a less secure learning environment out of the fear that they may be the next victims and the thoughts that parents and teachers may be unwilling or unable to control these bullies' behavior.

Bullies also suffer long-term effects, just like the victims. First, they focus more on fellow bullying students, which draws their attention from studies resulting in academic difficulties. Secondly, they are feared by their peers, and therefore they lack genuine friendships and relationships. These bullies' social supports are also impacted since it is tough to maintain interpersonal relationships with them, thereby experiencing peer rejection and therefore tend to associate with antisocial peer groups (Rigby, 2011). Aggression is consistent over time for some people, which indicates that bully children may continue with the hostile behavior into adulthood. Consequently, as aggressive adults, they may tend to continue with workplace harassment and domestic violence.

Peers happen to see when bullying is done and contribute, influence or pressure both parties either intentionally or unintentionally. These peers play a crucial role in diffusing a bullying incident or any other pivotal role. Some of them contribute to bullying, others stay out of it, and others intervene to comfort and defend the victim. Some children successfully evade being bullied by adopting a prosocial approach when engaging with their peers by effectively controlling their emotions (Evans \& Smokowski, 2015). Prosocial children give others the benefit of the doubt, establish goals to facilitate achievement and maintain positive relationships, and respond to provocation with high moral standards. Even when provoked by peers, they are not stresses since their emotions are well regulated.

\section{CONCLUSION}

Bullying is a common thing, especially in schools. It is characterized by a power hierarchy where some children feel that they belong to a higher power level than others hence abusing them in one way or another. Bullying is not a one-time thing, as the bullies do it repetitively. Bullying can occur in different forms, including physical abuse, verbal 
abuse, alienation, or even online/cyberbullying. The effects of cyberbullying are both short-term and long-term and affect the victim, the bully, and their peers. The victims suffer the most impact as their physical health can be harmful; they can get anxiety, stress, and depression, ending up being always angry or withdrawn. They are still full of fear, which turns their attention from books, and may even hate school, which leads to poor academic performance. To the extreme, the victims have suicidal thoughts, and some of them commit suicide. The bullies are unlikely to drop this behavior and, therefore, contribute to a chaotic society as they harass their workmates and engage in abusive relationships. Also, their peers who are present as bullying occurs may fear being at school as they are helpless in defending their peers from bullying.

\section{REFERENCES}

Dresler-Hawke, E., \& Whitehead, D. (2013). The behavioral ecological model as a framework for school-based anti-bullying health promotion interventions. The Journal of School Nursing, 25(3), 195-204.

Evans, C. R., \& Smokowski, P. R. (2015). Prosocial bystander behavior in bullying dynamics: Assessing the impact of social capital. Journal of Youth and Adolescence, 44(12), 2289-2307.

Ghani, S. A., Awang, M. M., Ahmad, A. R., Jalal, B., \& Bakar, A. Y. A. (2020). Fenomena Buli dan Gangsterisme: Satu Kajian Empirikal. Kuala Lumpur: UPNM Press.

Jan, A., \& Husain, S. (2015). Bullying in elementary schools: Its' causes and effects on students. Journal of Education and Practice, 6(19), 43-56.

Omoteso, B. A. (2010). Bullying behaviour, its' associated factors and psychological effects among secondary students in Nigeria. Journal of International Social Research, 3(10), 498-509.

Rigby, K. (2011). Health consequences of bullying and its prevention. Peer harassment in school: The plight of the vulnerable and victimized, 310.

Rivara, F., \& Le Menestrel, S. (2014). Committee on the Biological and Psychosocial Effects of Peer Victimization: Lessons for Bullying Prevention. National Academies of Sciences, Engineering, and Medicine. Washington (DC).

UNESCO. (2018). School violence and bullying: Global status and trends, drivers and consequences. 